\title{
Patterns of Corrective Feedback and Uptake in an Adult ESL Classroom
}

\section{ILIANA PANO VA AND ROY LYSTER}

McGill University

Montreal, Quebec, Canada

This article begins by synthesizing findings from observational classroom research on corrective feedback and then presents an observational study of patterns of error treatment in an adult ESL classroom. The study examines the range and types of feedback used by the teacher and their relationship to learner uptake and immediate repair of error. The database consists of 10 hours of transcribed interaction, comprising 1,716 student turns and 1,641 teacher turns, coded in accordance with the categories identified in Lyster and Ranta's (1997) model of corrective discourse. The results reveal a clear preference for implicit types of reformulative feedback, namely, recasts and translation, leaving little opportunity for other feedback types that encourage learner-generated repair. Consequently, rates of learner uptake and immediate repair of error are low in this classroom. These results are discussed in relation to the hypothesis that L2 learners may benefit more from retrieval and production processes than from only hearing target forms in the input.

\footnotetext{
C orrective feedback has recently gained prominence in studies of ESL 1 and other L2 education contexts, as a number of researchers have looked specifically into its nature and role in L2 teaching and learning (e.g., Doughty \& Varela, 1998; Havranek, 1999; Lyster \& Ranta, 1997; Ohta, 2000; Oliver, 2000). Much of this research has been motivated by the theoretical claim that, although a great deal of L2 learning takes place through exposure to comprehensible input, learners may require negative evidence (i.e., information about ungrammaticality), in the form of either feedback on error or explicit instruction, when they are not able to discover through exposure alone how their interlanguage differs from the L2 (e.g., Bley-Vroman, 1986; Rutherford \& Sharwood Smith, 1985, 1988; White, 1987). If corrective feedback is sufficiently salient to enable learners to notice the gap between their interlanguage forms and target language forms (Schmidt \& Frota, 1986), the resulting cognitive comparison may trigger a destabilization and restructuring of
} 
the target language grammar (Ellis, 1994; Gass, 1997). An additional effect of corrective feedback may be the enhancement of learners' metalinguistic awareness (Swain, 1995).

Following the tradition of early descriptive studies of classroom interaction, observational studies have been undertaken to describe patterns of error treatment by using increasingly fine-tuned models of corrective discourse. The present study builds on previous studies by drawing on one of these models to describe and analyze the error treatment process in an ESL classroom where the students are adults and the L2 instruction is within the communicative orientation of language teaching.

\section{O BSERVATIONAL CLASSR O OM ST UDIES OF FEEDBACK AND UPTAKE}

The overview of studies presented in this section examines relevant observational research on corrective feedback and learner uptake during oral classroom work. In reviewing classroom observational studies, we look for common patterns of error treatment in different classroom contexts that involve preferred corrective techniques as well as how specific types of feedback and error types correlate with learner uptake and repair. For the purposes of this overview, corrective feedback refers to "any reaction of the teacher which clearly transforms, disapprovingly refers to, or demands improvement of the learner utterance" (Chaudron, 1977 , p. 31). Uptake refers to different types of student responses immediately following the feedback, including responses with repair of the nontarget items as well as utterances still in need of repair (Lyster \& Ranta, 1997).

Based on an early study of classroom interaction in an adult ESL classroom, Allwright (1975) speculated that research on teacher feedback has the potential to provide information about the effectiveness of the instructional process and, ultimately, knowledge about how language learning takes place. His analysis included error types as well as teachers' options in responding to student errors (i.e., ignoring vs. correcting an error, immediate vs. delayed correction). His observations revealed that error treatment in the classroom is imprecise, inconsistent, and ambiguous. Similarly, Fanselow (1977), in an analysis of the corrective techniques of 11 teachers in adult ESL classrooms, found that feedback was confusing to learners in that the latter often received contradictory signals simultaneously with respect to the content and the form of their utterances. Among the 16 types of verbal and nonverbal teacher reactions to learner errors, the most common was the teacher's provision of 
the target language form (i.e., recasts); as a result, opportunities for selfrepair were minimal.

Chaudron (1977) developed a comprehensive model of corrective discourse, based on the data from his study of immersion classrooms. Its level of detail gave due credit to the complexity of the phenomenon of error treatment in a classroom setting. Chaudron's model was a significant step forward in attempting to identify various corrective techniques as well as a first serious attempt to look into the relationship between type of error, feedback, and learner repair. He found that the most common type of feedback used by teachers was reformulation of learner utterances, accompanied by various features such as emphasis, reduction, and negation, as well as expansion or unaltered repetition. In examining the relationship between feedback and immediate learner repair, Chaudron found a positive effect for repetitions with change (i.e., recasts) plus reduction and emphasis, whereas repetitions with change (i.e., recasts) plus expansion resulted in a low rate of learner repair.

Slimani's (1992) observational study of classroom interaction was not designed specifically to investigate error treatment, but its findings are relevant to the issue of feedback because of its innovative procedure of asking young adult students to complete recall charts on which they were to claim language items that they had noticed during ESL lessons. Classroom observations and audio recordings of the lessons allowed Slimani to conclude that students failed to claim $36 \%$ of the language items focused on during the lessons and that the majority of these unnoticed or "lost" items had been focused on as error correction. However, Slimani found that the instances of error correction that passed unnoticed had occurred when teachers reformulated learner utterances implicitly, without any metalanguage or further involvement from students (i.e., recasts), as illustrated in the following example:

L: $\quad \ldots$ I looking for my pen.

T: You are looking for your pen. (Slimani, 1992, p. 212)

In contrast to this, Slimani gave several examples of items that students claimed as being noticed. Among these were items that had arisen incidentally during classroom interaction, targeted by more elicitative types of feedback, as in the following example:

T: OK. Did you like it?

L: Yes, yes, I like it.

T: Yes, I . . ?

L: $\quad$ Yes, I liked it.

T: $\quad$ Yes, I liked it. (Slimani, 1992, p. 208) 
Thus, learners claimed to notice forms that they were pushed to selfrepair more than forms that were implicitly provided by teachers.

In a similar vein, Roberts (1995) conducted a small-scale study with three adult learners of Japanese. He investigated their ability to identify instances of teacher feedback in a post hoc viewing of a video recording of a 50-minute lesson in which they and an unidentified number of other classmates had participated. One learner was able to identify $46 \%$ of the feedback moves in the 50-minute segment, another identified $37 \%$, and another only $24 \%$. Recasting was the predominant type of response to learner errors, constituting $60 \%$ of all feedback. Roberts coded many of the recast moves as partial recasts because they shortened the learner's utterance to isolate the error, and the learners were more likely to identify these as feedback moves although they were still unable to identify any more than $43 \%$ of these partial recasts.

Research on negative evidence in L1 acquisition motivated Doughty's (1994) study of corrective feedback with adult learners of French as a foreign language. In 6 hours of recorded classroom interaction, the teacher provided corrective feedback after roughly half the students' illformed utterances, and recasts accounted for about $70 \%$ of these corrective feedback moves. Learners in this study responded with wellformed repetitions after only $21 \%$ of these recasts, a finding that appears to be at odds with Doughty's conclusion that the learners in this study tended to notice the teacher's feedback.

Lyster and Ranta (1997) analyzed 18.3 hours of teacher-student interaction in four Grade 4/5 French immersion classrooms during subject-matter and French language arts lessons. Drawing on categories from previous models as well as adding new categories derived from the analysis of teacher-student interaction in these classrooms, the researchers developed an analytic model to code error treatment sequences in terms of corrective feedback types and learner uptake. Specifically, they identified six types of corrective feedback in the database: explicit correction, recasts, clarification requests, metalinguistic feedback, elicitation, and repetition of error. Two types of uptake (immediate learner responses) were identified, namely, uptake with repair and uptake with needs-repair. Furthermore, each type of uptake included additional possibilities regarding various levels of student responses. The notion of uptake enabled the researchers to identify different degrees of student participation in the error treatment sequence and thereby to describe various patterns of error treatment in teacher-student interaction. Uptake was not considered to be an instance of learning, although the authors speculated that certain types of uptake (i.e., those including learner-generated repair) are likely to benefit the development of target language accuracy.

The following patterns emerged from the analysis. First, teachers 
provided feedback on $62 \%$ of the erroneous utterances. Second, recasting of learner utterances was the most widely used type of feedback. Next, with respect to the relationship between type of feedback and learner uptake, recasts were the least successful type, and elicitation resulted in the highest rate of uptake. In addition, most learnergenerated repair occurred after elicitation and metalinguistic feedback. Lyster and Ranta (1997) argued that feedback types such as metalinguistic feedback, elicitation, clarification requests, and repetition of error create opportunities for negotiation of form by promoting more active learner involvement in the error treatment process than do feedback types that reformulate learner errors (i.e., recasts and explicit correction). In a subsequent study, Lyster (1998a) found that corrective sequences involving negotiation of form (i.e., feedback types that provide clues for selfrepair rather than correct reformulations) were more likely than recasts and explicit corrections to lead to immediate repair of lexical and grammatical errors, whereas recasts were found to be effective in leading to repair of phonological errors.

Using the same database, Lyster (1998b) analyzed the function and the distribution of different types of recasts and compared them with the distribution of teachers' noncorrective repetitions of well-formed utterances. The analyses revealed the potential for ambiguity of recasts from the learners' perspective, because the function and distribution of recasts following ill-formed utterances paralleled the function and distribution of noncorrective repetitions following well-formed learner utterances. Lyster suggested that the corrective purpose of recasts may not be the primary one, especially when they are accompanied by approval directed at the content of the ill-formed utterance, and argued that "recasts have more in common with non-corrective repetition and topic-continuation moves than with other forms of corrective feedback" (p. 71). Consequently, recasts, similar to noncorrective repetitions, can be perceived by learners as positive evidence (information about what is acceptable in the target language) rather than negative evidence (see also Long, 1996).

\section{RATIONALE AND RESEARCH QUESTIONS}

With respect to general patterns of error treatment, the results of classroom-based observational research on feedback and uptake reviewed in the previous section reveal that

1. Teachers have at their disposal a wide variety of corrective strategies to focus on learner errors.

2. Choice of feedback type can be dependent on type of error. 
3. Recasts are the most widely used type of feedback in the observed classrooms.

4. The discourse functions of recasts may lead classroom learners to confuse recasts with positive feedback moves.

5. Learner repair immediately following feedback can be either repetition or learner-generated repair, depending on the type of feedback used.

6. In comparison with other feedback types, recasts do not promote immediate learner repair, which, in the case of recasts, involves repetition.

7. Recasts that reduce the learner's utterance and add stress to emphasize the corrective modification are more effective at eliciting repetition of the recast and are more likely to be identified by learners as corrective feedback.

8. The corrective techniques of clarification request, elicitation, metalinguistic feedback, and repetition of error correlate more positively with learner uptake and immediate repair, and, in these cases, the repair is learner generated.

9. Learners claim to notice forms that they are pushed to self-repair more than forms that are implicitly provided by teachers.

The findings of observational research on feedback have motivated the present study. Of particular relevance is Lyster and Ranta's (1997) study of corrective feedback and learner uptake and, specifically, their analytical model of error treatment, which the present study applies to a different instructional setting. Lyster and Ranta's model was selected for the present analysis because (a) it provides a tool for identifying, in detail, individual teacher styles in the treatment of error during oral classroom interaction and (b) it facilitates an examination of how learners react to feedback in a variety of ways.

The primary aim of this study, therefore, is to examine the error treatment patterns, involving the relationship between feedback types and how learners respond to them, in an adult ESL classroom. Its secondary aim is to ascertain whether Lyster and Ranta's (1997) model of corrective discourse is applicable in a different instructional context. Lyster and Ranta's study was conducted with young learners in French immersion classrooms with content-based L2 instruction. In contrast, the present study involves adult learners of English in an L2 classroom where the instruction targets the L2 within the realm of communicative language teaching. The study aims primarily to answer the following research question: Given adult learners in a context of communicative language teaching, which feedback types lead to the greatest amount of uptake? 
To answer this question, we first identify the various feedback types used in this classroom. Further, a comparison of our findings with those of Lyster and Ranta (1997) will be of theoretical interest in light of our prediction-namely, because adults are more intentional in their learning than children are, recasts may be more salient for adult learners than for children, and thus a higher rate of uptake following recasts is predicted in the adult classroom. We acknowledge, however, that whether or not learners repeat a recast may be inconsequential with respect to L2 learning, as suggested by Mackey and Philp's (1998) study (but see Swain, 1985, 1993, 1995; Kowal \& Swain, 1997, regarding the role of production in moving learners from semantic processing to syntactic processing). Uptake consisting of a repetition may not have much to contribute to L2 development because of its redundancy in an error treatment sequence in which the teacher both initiates and completes the repair within a single move. Yet uptake involving learner-generated repair may indeed contribute to language development, as suggested by Nobuyoshi and Ellis (1993), who found that the learners who responded with self-completed repair following clarification requests improved more than the learner who did not modify his output following the feedback. We return in the conclusion to the issue of retrieval processes and of which process is more likely to trigger a destabilization of interlanguage forms: (a) retrieval from external input and use of receptive skills to reanalyze linguistic representations or (b) retrieval via internal processes resulting in reanalysis and the production of modified output.

\section{METHOD}

\section{Participants}

The study was conducted over a period of 4 weeks in an adult educational centre ESL classroom in a Montreal school board in Quebec, Canada. The observations took place in a class of 25 students, whose ages ranged from 17 to 55 years. Twenty of the students were of Haitian background. Haitian Creole was their L1, but they also spoke French, which is the language of instruction in Haiti. Two students were from Quebec, one was from Guinea Conakry, one from Portugal, and one from the Dominican Republic. Therefore, this classroom was unlike many ESL classrooms in other North American contexts and elsewhere, and was instead more similar to EFL contexts, because so many of the students shared a common language other than English (i.e., French). All participants had completed at least presecondary schooling but varied in the extent to which they had completed their secondary 
schooling. The students had been placed in this Level 2 ESL course based on results obtained on tests in math, French, and English.

Although Level 2 is an early intermediate level, the teacher considered the proficiency of the students in this group to be at a beginning level because of their problems in comprehension and their limited oral and written production abilities with respect to vocabulary and sentence structure. The use of French was widespread in this classroom when comprehension problems arose and when students were assigned pair and group work.

The teacher was a female French/English bilingual with 13 years' experience in teaching ESL to adults. She was chosen on the basis of her professional interest and willingness to participate in the study. She was informed that the study would examine aspects of classroom interaction but not that the specific focus was on corrective feedback.

\section{Instructional Context}

The aim of adult educational centres is to enable students to complete their high school studies and possibly pursue studies in higher educational institutions, such as vocational colleges or universities. The ESL program for adults consists of seven levels, and the successful completion of Levels 1-4 represents the minimum requirement for obtaining a high school diploma. The Level 2 course in the present study consisted of 90 hours distributed over a 9-week period; the 10 hours per week usually involved one 2-hour class per day.

The goal of the ESL program is for students to achieve a fair degree of communicative competence in English. The instructional approach of the program is within the communicative orientation of language teaching, with a strong emphasis on vocabulary development, speaking and listening comprehension, and, to a lesser degree, writing and reading. Focus on language form is brief and is discretely presented in the program materials as additional information for the students to consult at home or discuss with the teacher. Thus, activities that focus on linguistic form are minimal, and the evaluation of the students, which includes speaking, listening, reading, and writing measures, does not focus on accuracy of learner language. This means that teachers have to rely on personal choices as to whether and when to focus on formal features of the language, including provision of corrective feedback.

The observed classroom was particularly dynamic in that the teacher focused to a considerable extent on oral interactive activities and listening comprehension and to a lesser extent on written activities. Oral activities were conducted in such a way as to create a lively classroom atmosphere where, according to results obtained by using Part A of 
Spada and Fröhlich's (1995) Communicative Orientation to Language Teaching (COLT) coding scheme, the students and teacher were involved in oral exchanges $90 \%$ of the time. The most frequent oral activities were (a) role plays presented by pairs of students (e.g., eating at a restaurant, making travel arrangements) and (b) reading and listening comprehension activities (usually in the form of question-and-answer exchanges after reading a text or listening to a recorded conversation). Writing activities were usually brief and involved (a) filling in blanks in dialogues while listening to audio recordings, (b) short grammar exercises, and (c) occasional dictations. Students often completed these written tasks in pairs or in small groups.

\section{Procedure}

During observations of 18 hours of classroom interaction during Weeks 6-9 of the 9-week course, the first author, in addition to using COLT Part A, wrote field notes to capture specific contextual and paralinguistic features, such as gestures and the teacher's writing on the board. She also produced audio recordings for subsequent analysis by using two microphones that were placed on the walls of the classroom in such a way as to capture both the teacher's and the students' utterances: One was positioned close to the front of the classroom, and the other was placed at the back.

Of the 18 hours of recorded interaction, 10 hours, which constitute the present study's database, were transcribed by the first author. These 10 hours consist of one 2-hour lesson from Week 6, three 2-hour lessons from Week 7, and one 2-hour lesson from Week 8 . The database does not contain any lessons devoted only to grammar; rather, as anticipated, the teacher's focus on formal properties of the language was incorporated in the thematic structure of the lessons (some of the lesson topics were "Eating Out," "Going Shopping," and "Travel").

The categories used to code the data in the present study were adapted from the error treatment sequence delineated in Lyster and Ranta's (1997) model. The main unit of analysis was the error treatment sequence, which contains teacher and student turns in the following order:

- learner error

- teacher feedback

- learner uptake, with either repair of the error or needs-repair

This order reflects what usually happens when a teacher responds to an utterance containing an error and when the student attempts to respond to the teacher's feedback move. In other cases, teacher-initiated or 
student-initiated topic continuation may follow learner error, teacher feedback, uptake with repair, or uptake with needs-repair.

All student utterances were included in the analysis. We did not exclude incomplete or brief utterances because we felt that they were important in analyzing learner language at this beginning stage of the students' L2 development.

All student utterances with errors were counted. Errors were coded as phonological, grammatical, or lexical. Even though the types of errors were isolated in the coding stage of the analysis, they were not the main subject of interest in this study; they were coded in order to trace general tendencies in the teacher's corrective patterns. Student utterances in the L1 were also included in the analysis in order to compare the teacher's responses to L1 use with her usual response to errors in the L2. Individual student turns that contained both French and English lexical items were considered nontargetlike and were included in the analysis as well.

The first author coded the data in accordance with the categories in Lyster and Ranta's (1997) model of error treatment, making minor modifications (discussed in the next section). The second author coded a randomly selected subsample of $16 \%$ of the feedback sequences, and a test of interrater reliability yielded a .86 level of agreement.

\section{Analysis}

\section{Feedback Types}

The teacher used seven types of corrective feedback: recast, translation, clarification request, metalinguistic feedback, elicitation, explicit correction, and repetition.

A recast (see Example 1) is an implicit corrective feedback move that reformulates or expands an ill-formed or incomplete utterance in an unobtrusive way, similar to the type of recasts provided by primary caregivers in child L1 acquisition (Long, 1996). ${ }^{1}$

1. S: Dangerous? (phonological error: /dange'rus/)

T: Yeah, good. Dangerous. (recast) You remember? Safe and dangerous. If you walk in the streets, you ...

Translation can be seen as a feedback move when it follows a student's unsolicited uses of the L1. Lyster and Ranta (1997) found very few of these moves in their database and so coded translations as recasts-due

\footnotetext{
${ }^{1}$ In the extracts, $\mathrm{T}=$ teacher, $\mathrm{S}=$ student; $\mathrm{SmS}=$ the same student, and DifS = a different student from the previous student turn.
} 
to their similar function of reformulating nontarget learner utterances. There is nevertheless a relevant difference between a recast (a response to an ill-formed utterance in the L2) and a translation (a response to a well-formed utterance in the L1). Because of the high number of such translations occurring in the present database, we coded these as a separate feedback category, an example of which follows:

2. T: All right, now, which place is near the water?

S: $\quad$ Non, j'ai pas fini. (L1)

T: You haven't finished? Okay, Bernard, have you finished? (translation)

The purpose of a clarification request is to elicit reformulation or repetition from the student with respect to the form of the student's illformed utterance. Often this type of feedback seeks clarification of the meaning as well. In the database, clarification requests were used when there were problems in the form that, as a result of the students' low proficiency level, also affected the comprehensibility of the utterance. Such is the case in Example 3, in which the student utterance is illformed to an extent that the teacher is not sure what the student means.

3. S: I want practice today, today. (grammatical error)

T: I'm sorry? (clarification request)

Although phrases such as I'm sorry and I don't understand are typical of clarification requests, another type occurred in the data, illustrated in Example 4. Interestingly, this type of clarification request clearly seeks to elicit self-repair from the student as the teacher responds literally to what the student has said. Here, there is no comprehension problem. The teacher seems to be aware of what the student wants to say and focuses him on the error without giving him the correct response but, via a clarification request, uses a clue that directs the student to the nature of the error, in this case temporal reference.

4. T: Okay. This is the name of your city in Haiti where you grew up. Yes?

S: $\quad$ Yeah, my city ...

T: $\quad$ Yeah, okay.

SmS: . . . where I live. (grammatical error)

$\mathrm{T}$ : $\quad$ Now? (clarification request)

SmS: Yeah ... where I was living. (repair)

According to Lyster and Ranta (1997), metalinguistic feedback (see Example 5) refers to "either comments, information, or questions related to the well-formedness of the student utterance, without explicitly providing the correct answer" (p. 46). 
5. S: $\quad$ Nouvelle Ecosse ... (L1)

T: Oh, but that's in French. (metalinguistic feedback)

Similar to the purpose of clarification requests and metalinguistic feedback, elicitation is a corrective technique that prompts the learner to self-correct. Lyster and Ranta (1997) identified three ways of eliciting the correct form from the students: (a) when the teacher pauses and lets the student complete the utterance, (b) when the teacher asks an open question, and (c) when the teacher requests a reformulation of the illformed utterance. Example 6 shows an instance of (a), in which the teacher elicits self-repair by pausing, expecting the student to provide the right lexical item.

6. S: $\quad$ New Ecosse. (L1)

T: $\quad$ New Ecosse. I like that. I'm sure they'd love that. Nova . . .? (elicitation)

SmS: Nova Scotia. (repair)

Example 7 represents the elicitation technique described in (b), which results in peer repair.

7. T: In a fast food restaurant, how much do you tip?

S: $\quad$ No money. (lexical error)

T: $\quad$ What's the word? (elicitation)

SmS: $\quad$ Five ... four ... (needs repair)

T: $\quad$ What's the word ... in a fast food restaurant? (elicitation)

DifS: Nothing (repair)

T: $\quad$ Nothing, yeah. Okay, what tip should you leave for the following.... (topic continuation)

Explicit correction provides explicit signals to the student that there is an error in the previous utterance, as shown in Example 8. Unlike recasts and translation, explicit correction involves a clear indication to the student that an utterance was ill-formed and also provides the correct form.

8. S: The day ... tomorrow. (lexical error)

T: $\quad$ Yes. No, the day before yesterday. (explicit correction)

In a repetition, the teacher repeats the ill-formed part of the student's utterance, usually with a change in intonation, as shown in Example 9.

9. T: $\quad$ T. Here, when you do a paragraph, you start here, well, let's see, anyway, you write .... write, write, write (pretends to be writing on the board), remember this is ... What is this called?

S: $\quad$ Comma. (lexical error) 


\section{T: Comma? (repetition)}

DifS: Period. (repair)

\section{Learner Responses to Feedback: Uptake and Repair}

In Lyster and Ranta's (1997) model, uptake in the error-feedback sequence refers to "a student utterance that immediately follows the teacher's feedback and that constitutes a reaction in some way to the teacher's intention to draw attention to some aspect of the student's initial utterance" (p. 49). Uptake does not occur when either (a) feedback is followed by teacher-initiated topic continuation, thus denying the students an opportunity to respond to feedback; or (b) feedback is followed by student-initiated topic continuation, that is, feedback fails to be verbally acknowledged and perhaps noticed, if noticing is measured by the presence of student response.

When feedback results in student uptake, the latter includes two possibilities that are represented by the categories of repair and needsrepair. According to Lyster and Ranta (1997), repair refers to "the correct reformulation of an error as uttered in a single turn and not to the sequence of turns resulting in the correct reformulation; nor does it refer to self-initiated repair" (p. 49). Repair can occur in the following forms: self-repair or peer repair of error, and repetition or incorporation of feedback.

Self-repair (shown in Example 9) occurs when teacher feedback, which does not include the correct form, prompts the student who committed the error to self-correct, whereas peer repair (shown in Example 10) is provided by a student different from the one who initially made the error.

10. S: C'est ça. Très chaud. (L1)

T: It's very . . ? (elicitation)

Sms: Hot. (self-repair)

11. S: I don't understand wine [win]. (phonological error)

T: $\quad$ I'm sorry ...? (clarification request)

SmS: Wine [win] (needs-repair/same error)

DifS: Wine [wain] (peer repair)

T: Wine? Red wine, white wine ... (topic continuation)

Self- and peer repair follow elicitative types of corrective feedback such as repetition, clarification requests, metalinguistic feedback, and elicitation. Repetition and incorporation usually follow recasts, explicit correction, or translation, because these feedback types include the target form, which can be repeated or incorporated in a longer utterance, as shown respectively in Examples 12 and 13. 
12. S: Yes, I have to ... to find the answer on ... on the book also? (grammatical error)

T: $\quad$ In the book, yes. Both . . . in the book. (recast)

SmS: In the book. (repair/repetition)

13. T: Okay, it's good. You wanna tell us one?

S: $\quad$ Eh . . : Kaii convention. (phonological error-stress)

T: What kind of convention? (recast)

SmS: Kaii convention . . . eh . . some people . . (repair/ incorporation)

The category of needs-repair refers to a situation in which the student has responded to the teacher's feedback move in some way but the uptake has not resulted in repair. Lyster and Ranta (1997) identified six subcategories as needs-repair: acknowledgment, same error, different error, off-target, hesitation, and partial repair.

\section{RESULTS}

The database is composed of a total of 1,716 student turns and 1,641 teacher turns. Of the student turns, 857 (50\%) were ill-formed, were incomplete, or contained unsolicited use of the L1 (including turns coded as needs-repair). Of the teacher turns, 412 (25\%) included corrective feedback. This means that almost half (48\%) of the student turns with error or use of L1 received corrective feedback.

Of the seven types of feedback, recasting and translation of learner errors were used the most frequently, and recasts occurred in more than half of the feedback turns (see Table 1). Recasts and translation together accounted for $77 \%$ of the feedback moves in the database, thus leaving little opportunity for use of other corrective techniques (clarification request, 11\%; metalinguistic feedback, 5\%; elicitation, 4\%; explicit correction, $2 \%$; repetition, $1 \%$ ).

Learner uptake followed $192(47 \%)$ of 412 feedback moves. Only 65 of these uptake moves included learner repair, meaning that learner repair followed $16 \%$ of the feedback moves and that only $8 \%$ of the students' 857 errors were repaired after teacher feedback.

The relationship between type of corrective feedback and learner uptake and repair is presented in Table 2. The highest rates of learner uptake $(100 \%)$ occurred with clarification requests, elicitation, and repetition. Metalinguistic feedback was the next prominent indicator of learner uptake; $71 \%$ of the feedback moves with metalinguistic feedback resulted in learner uptake. When the teacher recast or explicitly corrected an error by providing the target form, uptake was lower, at $40 \%$ and $33 \%$ of the total number of these feedback types, respectively. The 
TABLE 1

Distribution of Corrective Feedback Moves $(N=412)$

\begin{tabular}{lrr} 
Feedback type & $n$ & $\%$ \\
\hline Recast & 226 & 55 \\
Translation & 91 & 22 \\
Clarification request & 44 & 11 \\
Metalinguistic feedback & 21 & 5 \\
Elicitation & 15 & 4 \\
Explicit correction & 9 & 2 \\
Repetition & 6 & 1 \\
\hline
\end{tabular}

lowest rate of uptake occurred when the teacher translated learner L1 utterances $(21 \%)$.

With respect to learner repair, rates of repair following recasts, translation, and explicit correction were the lowest, at 13\%, 4\%, and $0 \%$, respectively. As for the less frequently used types of feedback, teacher turns with repetition and elicitation resulted in the highest rate of learner repair ( $83 \%$ and $73 \%$, respectively), followed by feedback moves with metalinguistic feedback (29\%) and clarification requests $(23 \%)$. However, one needs to view these results with caution because of the low number of these feedback types and the consequent low number of uptake moves, which make the comparison of percentage distributions of uptake disproportionate to actual occurrences.

To summarize, the teacher provided corrective feedback following $48 \%$ of the student turns with error or use of L1. Of all the feedback types, recast and translation were the predominant corrective techniques in relation to the other types of feedback; they accounted for $77 \%$ of the total number of teacher feedback turns, recasts being the most widely used type of feedback. Slightly less than half of the total number of teacher feedback moves (47\%) resulted in student uptake, and only

TABLE 2

Uptake and Repair Moves Following Different Types of Feedback

\begin{tabular}{lrrrrr}
\hline \hline & \multicolumn{2}{c}{ Uptake moves } & & \multicolumn{2}{c}{ Repair moves } \\
\cline { 2 - 3 } Feedback type & $n$ & \% of feedback type & & \% of feedback type \\
\hline Recast $(n=226)$ & 90 & 40 & & 29 & 13 \\
Translation $(n=91)$ & 19 & 21 & & 4 & 4 \\
Clarification requests $(n=44)$ & 44 & 100 & & 10 & 23 \\
Metalinguistic feedback $(n=21)$ & 15 & 71 & & 6 & 29 \\
Elicitation $(n=15)$ & 15 & 100 & & 11 & 73 \\
Explicit correction $(n=9)$ & 3 & 33 & & 0 & - \\
Repetition $(n=6)$ & 6 & 100 & & 5 & 83 \\
\hline
\end{tabular}


about one third of the uptake moves included repair. In effect, repair of learner error followed only $16 \%$ of the total number of feedback turns.

\section{DISCUSSION}

The present study aimed to examine the patterns of error treatment in an adult ESL classroom. In particular, the analysis centered, first, on the frequency distribution of the different feedback types used by the teacher and, second, on the relationship between feedback types and learner responses to feedback.

Identification of seven different feedback types and a subsequent analysis of their frequency distribution showed that recasts were the most frequently used type of feedback, accounting for $55 \%$ of all feedback moves. This finding parallels findings obtained in other observational studies with child and adult language learners (Doughty, 1994; Fanselow, 1977; Lyster \& Ranta, 1997; Roberts, 1995). The second most frequent feedback type was translation, accounting for $22 \%$ of all feedback moves. Somewhat surprising was the limited use of the other feedback types, which accounted for the remaining 23\% of all feedback moves. This means that the teacher strongly preferred to use reformulative techniques, such as recasts and translation, rather than feedback types that prompt students to self-repair.

With respect to recasts, the students' low proficiency level may not have allowed the teacher to use other feedback types that invite greater student participation in negotiating form. That is, the students' limited linguistic resources, as evidenced by the great number of incomplete or brief utterances, may have predisposed the teacher to focus on means of providing linguistic input via reformulations. Thus, the teacher may have viewed recasts as a suitable strategy for providing exemplars of the target language. Evidence that proficiency level may affect teachers' choice of feedback and opportunities for uptake can be found in Lyster and Ranta's (1997) study. They reported that the teacher of the most advanced class tended to recast learner errors to a lesser degree than the other three teachers did. This class was also reported as having the highest rates of uptake and repair.

Further analysis of the data led to some insight into the relationship between individual readiness and the ability to notice recasts. At the end of the class in the first observation session, a student asked the teacher why she did not correct his errors. The teacher responded that she had to attend to the errors of the other students, too. As it turned out, this student was more vocal than most of the students in the class, possibly due to his higher proficiency level. An analysis of the student's responses to feedback revealed that his responses accounted for $19 \%$ of the total 
student uptake and for $31 \%$ of the total number of turns with repair. Interestingly, with respect to uptake following recasts, this student also provided as much as $53 \%$ of the total number of turns with repair following recasts. This means that the overall class response to recasts was even lower, which in turn suggests that recasts may be noticeable as negative evidence by more proficient learners (less proficient learners may nonetheless benefit from the positive evidence that recasts are able to provide). At least three other studies have suggested that recasts may allow more advanced learners to infer negative evidence but may pass unnoticed by less advanced learners (Lin \& Hedgcock, 1996; Mackey \& Philp, 1998; Netten, 1991).

With respect to translation as a corrective technique, the provision of target language exemplars via translation equivalents may have again been necessitated by the low proficiency level of the students. Further, the fact that the teacher responded to a well-formed utterance in the learners' L1 with translation gives it a status that is different from that of other feedback types, which may in turn explain why translation resulted in the lowest rate of uptake and repair (21\% and $4 \%$, respectively). The students may not have viewed translation as a corrective move in the same way they perceived other feedback types, as signaled by the higher rates of uptake and repair following these moves. The teacher's use of translation seems to have aimed not so much at provoking a response from the students but rather at providing additional language input to the students, given their low proficiency level. Similarly, Lyster (1998a) reported that teachers in his study showed "high tolerance for uses of L1 and low expectation that they should be repaired" (p. 205) and attributed this finding to three of the four classes being in only their first year of an immersion program.

In the present study, slightly less than half of the feedback turns resulted in learner uptake, and repair followed only $16 \%$ of them. In light of the fact that the teacher devoted one quarter of her turns to providing corrective feedback, the low level of student uptake is somewhat surprising. However, this finding simply parallels the finding that recasts and translation were used extensively and that these two feedback types tend to yield low rates of uptake and repair. As in Lyster and Ranta's (1997) study, we found higher rates of uptake for repetition of error, clarification requests, elicitation, and metalinguistic feedback. In the case of explicit correction, although it was rarely used $(n=9)$, it is noteworthy that this type of feedback resulted in uptake on only three occasions, none of which involved repair. One may wonder about the role of feedback that never leads to learner repair; however, in Lyster and Ranta's database, explicit correction was more successful at leading to repair than in the present database.

With respect to immediate repair of error, the results point decisively 
in favour of elicitation and repetition of error (with emphasis). Although these types of feedback occurred infrequently in the database, they invited the highest rate of student repair. As for feedback turns with clarification requests, even though uptake was high at $100 \%$, learner repair occurred in less than one quarter of the students' responses to clarification requests, comparable to the rate of repair in the learner responses following metalinguistic feedback.

\section{CONCLUSION}

The instructional settings observed in Lyster and Ranta's (1997) study and in the present study are similar in one important respect: Students in both settings were characterized by a certain degree of linguistic homogeneity in that, for the most part, they shared a common language other than the target language (i.e., English in the immersion context and French in the ESL context). At the same time, the settings differ in three important ways: (a) the age of the students (children vs. adults), (b) the instructional context and language of instruction (content-based instruction in a French immersion context vs. communicative ESL instruction), and (c) the level of proficiency (intermediate-level proficiency in the immersion classrooms vs. beginning-level proficiency in the ESL classroom). In spite of these differences, Lyster and Ranta's model and its coding categories proved to be applicable in the present study, with only minor revisions: namely, the addition of translation as a separate feedback category and the inclusion of a type of clarification request that focused on the literal, unintended meaning of learner utterances. Results obtained by applying the model and its coding categories in these two different instructional contexts revealed both similarities and differences in patterns of error treatment.

The preferred type of feedback was recasting of student errors, accounting for slightly more than half of the feedback turns in both studies. However, the present study included a specific category for translation. (Lyster \& Ranta, 1997, coded translations as recasts.) Together, recasts and translation accounted for more than three quarters of all feedback moves in the present study. Consequently, feedback techniques other than recasts and translation were used only minimally in the adult ESL classroom.

Overall rates of uptake and repair in the ESL classroom proved to be lower than in the immersion classrooms. These lower rates may be a result of the most frequently used types of feedback, namely, recasts and translation, which were used even more frequently in the ESL classroom than in the immersion classrooms. Because the function of both recasts and translations is to reformulate learner utterances by providing the 
correct model, they do not necessarily require student responses. In contrast, other feedback types, such as repetitions, clarification requests, elicitation, and metalinguistic feedback, are generally more successful at leading to immediate repair of learner errors and are able to prompt peer and self-repair. The results of the present study parallel results from other studies concerning teachers' tendency to use extensive recasting at the expense of these other types of feedback.

With respect to the relationship between feedback type and learner uptake, the similarity of findings is noteworthy. In both studies, corrective techniques that promote negotiation of form by allowing students the opportunity to self-correct or to correct their peers resulted in the highest rates of uptake. The fact that, in both studies, elicitation, clarification requests, repetition, and metalinguistic feedback reached comparably high levels of uptake indicates that these feedback moves tend to be noticed by students, insofar as "uptake may be related to learners' perceptions about feedback at the time of feedback" (Mackey, Gass, \& McDonough, 2000, p. 492). In contrast, both studies demonstrate that feedback types that provide learners with target formsnamely, (a) implicit, reformulative types of feedback such as recasts and translation, and (b) explicit correction-tend not to push students to modify their nontarget output in their responses immediately following feedback.

Thus, if recasts and translations are essentially corrective in purpose, there is little evidence that L2 learners in the present study processed them as such. This does not mean, however, that teachers should abandon recasts. Recasts serve important communicative functions in classroom discourse. For example, they provide teachers with efficient and natural ways of responding to students and, at the same time, provide students with supportive, scaffolded help in using their L2 (Lyster, 2002). Moreover, recasts help keep students' attention focused on content and move the lesson ahead when the forms in question are well beyond the students' current interlanguage (Lyster, 1998b). In this way, recasts provide considerable positive evidence, but they should not be advocated as the most effective way of providing negative evidence. Recasts may nonetheless be more effective when provided consistently after preselected errors, particularly when used in tandem with other more explicit signals, such as repetition of error with added intonational stress (Doughty \& Varela, 1998) or a reduction of the learner's utterance to locate the error, again with added stress for emphasis.

Swain and Lapkin (1995) propose that feedback, whether internally or externally generated, enables learners to notice problems in their output and pushes them to conduct an analysis leading to modified output. What occurs between the first and second output, they suggest, is part of the process of L2 learning. However, in the case of external 
feedback, the extent to which cognitive processes are activated between the learner's first and second output depends on the type of feedback. On the one hand, on the small number of occasions when learners modify their nontarget output after a recast, the modification may only be a mechanical repetition of the alternative form provided by the teacher, in which case the learner's attention is neither invested in the retrieval of alternative forms nor even drawn to the mismatch. On the other hand, in the case of opportunities for uptake following negotiationof-form moves, learners are pushed to draw on their own resources to modify or reprocess (Swain, 1995) their nontarget output. To do so in the case of self-completed repair, learners must attend to the retrieval of alternative forms.

According to de Bot (1996), language learners are likely to benefit more from being pushed to retrieve target language forms than from merely hearing the forms in the input, because the retrieval and subsequent production stimulate the development of connections in memory. This argument finds some support in the results of experimental studies of the generation effect (e.g., Buyer \& Dominowski, 1989; Clark, 1995; Grosofsky, Payne, \& Campbell, 1994; Slamecka \& Graf, 1978), whereby participants remember items that they have generated in response to cues better than they remember items merely provided to them.

Ellis (1997) distinguishes between two types of acquisition: (a) acquisition as the internalization of new forms and (b) acquisition as an increase in control over forms that have already been internalized (see also Bialystok \& Sharwood Smith, 1985). Possibly, by serving as exemplars of positive evidence, recasts facilitate the internalization of new forms while negotiation of form techniques enhance control over already-internalized forms. In this view, continued recasting of what students already know is unlikely to be the most effective strategy to ensure continued development of target language accuracy and may even have a leveling-off effect on their L2 development. Similarly, continued prompting of learners to draw on what they have not yet acquired will be equally ineffective. A balance, therefore, of different feedback types selected in the light of various contextual, linguistic, and cognitive factors is likely to prove more successful than overusing any one type of feedback.

\section{ACKN O WLEDGMENTS}

This study was undertaken by the first author in partial fulfillment of the requirements for her master's degree in TESL at McGill University. The study was funded in part by the Professional Improvement Committee of the English Montreal School Board and in part by the Social Sciences and Humanities Research Council of 
Canada (410-94-0783 and 410-98-0175). We gratefully acknowledge the participation of the teacher, her students, and the school board, as well as comments from Patsy Lightbown, Nina Spada, and Leila Ranta on earlier versions of this article. We also thank André Mather for his assistance in verifying the French transcriptions.

\section{THE AUTHORS}

Iliana Panova is a $\mathrm{PhD}$ candidate in the Department of Integrated Studies in Education at McGill University and a participant in McGill University's interdisciplinary $\mathrm{PhD}$ program in language acquisition. She is a literacy teacher in the adult sector of the English Montreal School Board.

Roy Lyster is an associate professor of second language education and codirector of graduate programs in the Department of Integrated Studies at McGill University. He is convener of the Scientific Commission on Immersion Education for the International Association of Applied Linguistics.

\section{REFERENCES}

Allwright, R. L. (1975). Problems in the study of the language teacher's treatment of learner error. In M. Burt \& H. Dulay (Eds.), New directions in second language learning, teaching and bilingual education: On TESOL '75 (pp. 96-109). Washington, DC: TESOL.

Bialystok, E., \& Sharwood Smith, W. (1985). Interlanguage is not a state of mind. Applied Linguistics, 6, 101-117.

Bley-Vroman, R. (1986). Hypothesis testing in second-language acquisition theory. Language Learning, 36, 353-376.

Buyer, L., \& Dominowski, R. (1989). Retention of solutions: It is better to give than to receive. American Journal of Psychology, 102, 353-363.

Clark, S. (1995). The generation effect and the modeling of associations in memory. Memory E Cognition, 23, 442-455.

de Bot, K. (1996). The psycholinguistics of the output hypothesis. Language Learning, $46,529-555$.

Doughty, C. (1994). Fine-tuning of feedback by competent speakers to language learners. In J. Alatis (Ed.), Georgetown University Round Table on Languages and Linguistics 1993: Strategic interaction and language acquisition (pp. 96-108). Washington, DC: Georgetown University Press.

Doughty, C., \& Varela, E. (1998). Communicative focus on form. In C. Doughty \& J. Williams (Eds.), Focus on form in classroom second language acquisition (pp. 114138). New York: Cambridge University Press.

Ellis, R. (1994). A theory of instructed second language acquisition. In N. Ellis (Ed.), Implicit and explicit language learning (pp. 79-114). London: Academic Press.

Ellis, R. (1997). SLA research and language teaching. Oxford: Oxford University Press.

Fanselow, J. (1977). The treatment of error in oral work. Foreign Language Annals, 10, $583-593$.

Gass, S. (1997). Input, interaction, and the second language learner. Mahwah, NJ: Erlbaum.

Grosofsky, A., Payne, D., \& Campbell, K. (1994). Does the generation effect depend upon selective displaces rehearsal? American Journal of Psychology, 107, 53-68.

Havranek, G. (1999). The effectiveness of corrective feedback: Preliminary results of 
an empirical study. Acquisition et interaction en langue étrangère: Proceedings of the Eighth EUROSLA Conference, 2, 189-206.

Kowal, M., \& Swain, M. (1997). From semantic to syntactic processing: How can we promote metalinguistic awareness in the French immersion classroom? In R. K. Johnson \& M. Swain (Eds.), Immersion education: International perspectives (pp. 284-309). Cambridge: Cambridge University Press.

Lin, Y.-H., \& Hedgcock, J. (1996). Negative feedback incorporation among highproficiency and low-proficiency Chinese-speaking learners of Spanish. Language Learning, 46, 567-611.

Long, M. H. (1996). The role of the linguistic environment in second language acquisition. In W. Ritchie \& T. Bhatia (Eds.), Handbook of second language acquisition (pp. 413-468). New York: Academic Press.

Lyster, R. (1998a). Negotiation of form, recasts, and explicit correction in relation to error types and learner repair in immersion classrooms. Language Learning, 48, 183-218.

Lyster, R. (1998b). Recasts, repetition, and ambiguity in L2 classroom discourse. Studies in Second Language Acquisition, 20, 51-81.

Lyster, R. (2002). The importance of differentiating negotiation of form and meaning in classroom interaction. In P. Burmeister, T. Piske, \& A. Rohde (Eds.), An integrated view of language development: Papers in honor of Henning Wode (pp. 381397). Trier, Germany: Wissenschaftlicher Verlag Trier.

Lyster, R., \& Ranta, L. (1997). Corrective feedback and learner uptake: Negotiation of form in communicative classrooms. Studies in Second Language Acquisition, 19, $37-66$.

Mackey, A., Gass, S., \& McDonough, K. (2000). How do learners perceive implicit negative feedback? Studies in Second Language Acquisition, 22, 471-497.

Mackey, A., \& Philp, J. (1998). Conversational interaction and second language development: Recasts, responses, and red herrings? The Modern Language Journal, $82,338-356$.

Netten, J. (1991). Towards a more language oriented second language classroom. In L. Malavé \& G. Duquette (Eds.), Language, culture and cognition (pp. 284-304). Clevedon, England: Multilingual Matters.

Nobuyoshi, J., \& Ellis, R. (1993). Focused communication tasks and second language acquisition. ELT Journal, 47, 203-210.

Ohta, A. (2000). Rethinking recasts: A learner-centered examination of corrective feedback in the Japanese classroom. In J. K. Hall \& L. Verplaetse (Eds.), The construction of second and foreign language learning through classroom interaction (pp. 47-71). Mahwah, NJ: Erlbaum.

Oliver, R. (2000). Age differences in negotiation and feedback in classroom and pairwork. Language Learning, 50, 119-151.

Roberts, M. (1995). Awareness and the efficacy of error correction. In R. Schmidt (Ed.), Attention and awareness in foreign language learning (Tech. Report No. 9, pp. 162-182). Honolulu: University of Hawai'i, Second Language Teaching and Curriculum Center.

Rutherford, W., \& Sharwood Smith, M. (1985). Consciousness-raising and Universal Grammar. Applied Linguistics, 6, 274-282.

Rutherford, W., \& Sharwood Smith, M. (1988). Grammar and second language teaching. New York: Newbury House.

Schmidt, R., \& Frota, S. (1986). Developing basic conversational ability in a second language: A case study of an adult learner of Portuguese. In R. Day (Ed.), Talking to learn (pp. 237-326). Rowley, MA: Newbury House. 
Slamecka, N., \& Graf, P. (1978). The generation effect: Delineation of a phenomenon. Journal of Experimental Psychology: Human Learning and Memory, 4, 592-604.

Slimani, A. (1992). Evaluation of classroom interaction. In C. Anderson \& A. Beretta (Eds.), Evaluating second language education (pp. 197-221). Cambridge: Cambridge University Press.

Spada, N., \& Fröhlich, M. (1995). COLT. Communicative Orientation of Language Teaching observation scheme: Coding conventions and applications. Sydney, Australia: National Centre for English Language Teaching and Research.

Swain, M. (1985). Communicative competence: Some roles of comprehensible input and comprehensible output in its development. In S. Gass \& C. Madden (Eds.), Input in second language acquisition (pp. 235-253). Rowley, MA: Newbury House.

Swain, M. (1993). The output hypothesis: Just speaking and writing aren't enough. The Canadian Modern Language Review, 50, 158-164.

Swain, M. (1995). Three functions of output in second language learning. In G. Cook \& B. Seidlhofer (Eds.), Principles and practice in applied linguistics: Studies in honour of H. G. Widdowson (pp. 125-144). New York: Oxford University Press.

Swain, M., \& Lapkin, S. (1995). Problems in output and the cognitive processes they generate: A step towards second language learning. Applied Linguistics, 16, 370391.

White, L. (1987). Against comprehensible input: The input hypothesis and the development of L2 competence. Applied Linguistics, 8, 95-110. 